\title{
ANTIMALARIAL USE AND THE ASSOCIATED FACTORS IN RURAL NIGERIA FOLLOWING IMPLEMENTATION OF AFFORDABLE MEDICINES FACILITY-MALARIA (AMFM) PRICE SUBSIDY
}

\author{
RUNNING TITLE: ANTIMALARIAL USAGE FOLLOWING AMFM SUBSIDY
}

\author{
Efunshile#, A. M., Fowotade², A., Makanjuola², O.B., Oyediran³,E. I., \\ Olusanya ${ }^{2}$, O. O.\&Koenig, B1.

\begin{abstract}
1. Dept of Medical Microbiology and Infectious Disease Epidemiology, Leipzig University, Germany. 2.University of Ibadan,Dept of Medical Microbiology and Parasitology 3.Ladoke Akintola University of Technology Teaching Hospital, Dept of Medical Microbiology and Parasitology
\end{abstract} \\ \# Correspondence: e-mail-drefunshile@yahoo.comTel-No- +234-8169444998
}

\begin{abstract}
Purpose

This study was set out to find out the pattern of antimalarial drug use in a Nigerian rural community following the aggressive price subsidy of Artemisinin Combination Therapy(ACT) recently embarked upon by Roll Back Malaria partners through Affordable Medicines Facility-malaria (AMFm).

Methods

Questioners were administered to 310 adult members of the community with the most recent malaria episodes so as to find out about the drugs used and some of the factors associated with the choice of the drug.

Result

Although the overall use of ACT (13.55\%) in this community was about 4 times higher than what it used to be, Chloroquine $123(39.62 \%)$ and sulphadozine/pyrimathamine $120(38.71 \%)$ were the mostly used antimalarial agents. Choice of drug used was significantly associated with perception of efficacy and price among other factors. Respondents liked the price of ACT (33.3\%) most, CQ was the drug most liked in terms of efficacy (44.2\%) while SP was the drug most liked in terms of lack of side effect $(38.9 \%)$, taste $(61.6 \%)$ and convenience $(35.7 \%) .(P=0.001)$

Conclusion
\end{abstract}

In addition to sustaining the current price control, there is a need to continuously monitor and effectively regulate the quality of the ACTs in circulation so as to gain the confidence of both the prescribers and the end users regarding efficacy and adherence to ACTs. This will help to safeguard the huge investment in ACT subsidy by the Roll Back Malaria partners.

Key words: ACT, Subsidy, Affordable Medicines Facility-malaria

\section{INTRODUCTION}

The 2008 World Malaria Report showed that only 3\% of children with suspected malaria were treated with Artemisinin Combination Therapy (ACT), suggesting that many children were still receiving chloroquine and sulphadoxine/pyrimethamine for malaria treatment despite the recommended change in treatment guidelines [1]. A published study that evaluated 21 African countries for their antimalarial use in 2006-2007 showed that only three countries reported high use of the regimen that was in agreement with the national treatment guideline [2]. The study further revealed that chloroquine was the most common anti-malarial reported in 14 of 21 countries, and reported use was particularly high in West Africa.

A descriptive study that evaluated the anti-malarial drug prescribing practice in private and public health facilities in South-East Nigeria also showed that only $3.0 \%$ of patients were treated with artemisinin combination therapy. Most of the patientswere treated with chloroquine $(30.2 \%)$, sulphadoxine/ pyrimethamine $(22.7 \%)$ orartemisininmonotherapy (15.8\%) despite the change in the national malaria treatmentpolicy [3].

Treatment of malaria in pregnancy was not exempted from the protocolviolation. A recent survey of the patterns of anti-malarial drug treatment among pregnantwomen in Uganda showed that only $5.6 \%$ of the pregnant women in their first semesterwere treated according to the national guideline while $70 \%$ were treated withcontraindicated anti-malarial drugs. Recommended antimalarial were used according tothe guidelines in only $30.1 \%$ of all second and third trimester episodes [4].Some of the factors that that 
have been found to positively influence the use of clinical

guidelines include clarity of guidelines, strong evidence, adequate funding of guidelines and support by opinion leaders especially professional bodies [5].The reluctance to abandon chloroquine is based, in part, on its low cost, wide availability, and acceptance. Chloroquine results in rapid initial improvement of clinical symptoms, which has contributed to its widespread acceptance and the perception that it remains effective, leading to an unwillingness of both health workers and patients to discontinue using chloroquine despite its reduced efficacy [6].In 2004, Nigeria changed from the use of chloroquine and sulphadoxine/pyrimethamine as first line anti-malarial drugs in line with the recommendation of the World Health Organization as a result of unacceptably high level of resistance to the formal drugs [7].Adherence of patients as well as health care providers to the new guidelines remain poor in many parts of Nigeria [8-10].

Research data from Kenya provided strong evidence that continued use of chloroquine in areas with resistance was contributing to excess Plasmodium falciparum related deaths [6].Apart from vector and parasite biology, pharmacokinetics, and economics reasons;human behavior is another factor that has been associated with antimalarial drugresistance [11].In addition to low usage of ACTs imposed by its high cost, quality of ACTs in circulationis another major challenge. Recent survey by the World Health Organization (WHO) inconjunction with Nigerian drug regulation agency showed that Nigeria has the highestrate of sub-standard antimalarials (63.9\%) in Sub-Sahara Africa [1]. The survey furtherrevealed that a common problem for ACTs was that of lower content of active pharmaceutical ingredients (APIs). This was further supported by the findings of the Global Funds which showed that availability of quality-assured ACTs in Nigeria is only $28 \%$ [1].

The first attempt to improve the use of ACT in Nigeria was in 2008 when the government took a step forward in subsidizing child doses of Amodiaquineartesunate combination (ASAQ) via the private sector in 18 of the 37 states. Retailers in these 18 states could purchase subsidized ACTs for 5 naira (\$0.03 USD) per treatment with an approved retail price set at 30 naira (\$0.20 USD). This was followed by widespread stockouts of ACTs across Nigeria as a result of inadequate supply. This resulted in reduced availability of ACTs in the public sector and increased prices in the private sector. End users were eventually forced to revert back to the cheaper monotherapy [13].
Efforts to remove the obstacle imposed by high cost and stockouts of ACTs received another boost when Nigeria initiated Affordable Medicines Facilitymalaria (AMFm) activities on October 5, 2010. AMFm was set by the Roll Back Malaria Partnership (RBM) in 2007 and managed by the Global Fund to Fight AIDS, Tuberculosis and Malaria (the Global Fund).

The AMFm aims to increase use of ACTs by subsidizing prices of ACTs at the "factory gate". The subsidy will in turn be passed along the supply chain to the consumer, lowering ACT prices so that they are comparable to chloroquine, sulfadoxinepyrimethamine or artemisininmonotherapy. Reduced prices should, in theory, "crowd out" sales of these other drugs and thus increase ACT use [13].

The aim of this study is to find out the current malaria treatment practices following the introduction of

AMFm and some of the factors that are associated with such practices in a rural community in SouthWest Nigeria.

\section{METHODS}

This study was carried out between March and April 2012 at Oke-iho, a rural community in Oyo State, South-West Nigeria with a population of about 12,964 inhabitants. It is situated at $8.03^{\circ}$ North latitude, $3.35^{\circ}$ East longitude and 314 meters elevation above the sea level, the climate is tropical rainforest with malaria transmission occurring most of the year [13-14]. Information about the number of streets and houses in this community was obtained from the local government authority. Eleven houses were randomly selected from each street by simple random sampling method, and then an adult with the most recent episode of malaria was chosen as participant per house after informed consent was obtained. Pretested questionaires were administered by trained research assistants to participants after translation of the contents to their local dialects.

\section{Statistical analysis}

Data was analyzed with the free GNU PSPP Statistical Analysis Software version 0.7.9-gd4ae90. Using the descriptive statistics in the analysis command, frequency tables were generated for the general characteristics of the participants and expressed in percentages. Association between the drug used to treat the last malaria episode and other variables was assessed using Chi-Square, and $\mathrm{p}<0.05$ was taken to be significant.

\section{RESULTS}

Majority (58.71\%) were females while 201 (64.84\%) were married (table 1).Malaria was the $4^{\text {th }}$ common health problem $49 \quad(15.16 \%)$ experienced by participants and it was experienced once to twice a 
year in most cases (41.61\%) presenting as fever 126 $(40.65 \%)$ and headache $86(27.74 \%)$ (Table 2$)$.

TABLE 1: SOCIODEMOGRAPIC PARAMETER OF THE RESPONDENTS

\begin{tabular}{|c|c|c|}
\hline Character & frequency & $\%$ \\
\hline \multicolumn{3}{|l|}{ Age } \\
\hline $18-20$ & 50 & (16.13) \\
\hline $21-30$ & 114 & (36.77) \\
\hline $31-40$ & 87 & (28.06) \\
\hline $41-50$ & 31 & (10.02) \\
\hline$>50$ & 28 & $(9.03)$ \\
\hline \multicolumn{3}{|l|}{ Sex } \\
\hline Male & 128 & (41.24) \\
\hline Female & 182 & (58.71) \\
\hline \multicolumn{3}{|l|}{ Marital status } \\
\hline Married & 201 & (64.84) \\
\hline Single & 09 & (35.16) \\
\hline Separated & 0 & (0) \\
\hline \multicolumn{3}{|l|}{ Level of education } \\
\hline No formal education (Nil) & 27 & $(8.71)$ \\
\hline Primary school certificate & 40 & (12.90) \\
\hline Secondary school certificate & 163 & (52.58) \\
\hline Diploma & 69 & (22.26) \\
\hline Degree & 11 & (3.55) \\
\hline \multicolumn{3}{|l|}{ Occupation } \\
\hline Unemployed & 0 & (3.23) \\
\hline Students & 68 & (21.94) \\
\hline Trading & 81 & (26.13) \\
\hline Farming & 20 & (6.45) \\
\hline Artisan & 61 & (19.68) \\
\hline Teaching & 37 & (11.94) \\
\hline Apprentice & 7 & (2.26) \\
\hline Civil servants & 10 & (3.23) \\
\hline Others & 16 & (5.16) \\
\hline \multicolumn{3}{|l|}{ Tribe } \\
\hline Yoruba & 284 & (91.61) \\
\hline Ibo & 7 & (2.26) \\
\hline Hausa & 14 & (4.52) \\
\hline Fulani & 4 & (1.27) \\
\hline Ghanaian & 1 & $(0.32)$ \\
\hline
\end{tabular}

Sulphadozine/pyrimathamine 92(29.68\%) was mostly regarded as the currently recommended drug for treating malaria followed by chloroquine $85(27.42 \%)$. The drug used to treat the last episode of malaria by respondents included chloroquine 123(39.62\%), sulphadozine/pyrimathamine $120(38.71 \%), \quad$ ACT 82(13.55\%) and Artesunatemonotherapy 8 (2.58\%) (Table 3).CQ was mostly used by males (42.2\%) while SP was mostly used by females (39.0\%).

Use of ACT observed among females (15.9\%) was about 1.6 times higher than in the males $(10.2 \%), \mathrm{p}=$ 0.56 . While the use of SP has no definite pattern with the level of education, ACT use increased with the level of education, with the highest among those with university degree (27.2\%) while the use of CQ was highest among those with no formal education 14 (15.8\%), P=0.33, (Table 4).

TABLE 2:. MALARIA FEATURES AMONG PARTICIPANTS

\begin{tabular}{|llc|}
\hline Features & Frequency & $\%$ \\
\hline $\begin{array}{l}\text { What is your commonest } \\
\text { health problem? }\end{array}$ & & \\
Headache & 95 & $(30.65)$ \\
Back pain & 50 & $(16.13)$ \\
General body aches & 94 & $(30.32)$ \\
Malaria & 49 & $(15.16)$ \\
Menstrual pain & 3 & $(0.79)$ \\
Abdominal pain & 2 & $(0.65)$ \\
Others & 19 & $(6.13)$ \\
& & \\
How often do you & & \\
experience malaria attack? & & \\
< once per year & 39 & $(12.58)$ \\
1-2 times per year & 29 & $(41.61)$ \\
3-4 times per year & 91 & $(29.35)$ \\
4-6 times per year & 49 & $(15.81)$ \\
$>6$ times per year & 2 & $(0.65)$ \\
& & \\
What major sign suggest & & \\
that you have malaria? & & \\
Fever & 126 & $(40.65)$ \\
Headache & 86 & $(27.74)$ \\
Diarrhea & 11 & $(3.55)$ \\
Loss of appetite & 50 & $(16.13)$ \\
Body weakness & 36 & $(11.61)$ \\
Others & 1 & $(0.32)$ \\
& & \\
& & \\
\hline
\end{tabular}

Friends 7(50.0\%) and Chemists 15 (33.3\%) were more likely to prescribe CQ than any other drug. Doctors 26 $(19.3 \%)$ were the most likely to prescribe ACT followed by nurses (15.4\%). P=0.001. ACT was mostly liked for its good price (33.3\%), CQ was the drug mostly liked in terms of efficacy $(38.1 \%)$ while SP was the drug mostly liked in terms of lack of side effect $(38.9 \%)$, taste $(61.6 \%)$ and convenience $(35.7 \%)$. $\mathrm{P}=0.001$.

The use of CQ 76(89.4\%) and SP 70(76.1\%) were highest among those who believed that they were the recommended drugs for malaria while ACT 10(55.5\%) use was also highest among those who were of the opinion that it was the current antimalarial of choice. $\mathrm{P}=0.001$. (Table 5).

\section{DISCUSSION}

The overall use of $\mathrm{ACT}(13.55 \%)$ in this community was about 4 times higher than recorded in 2008 [1]. This may be a reflection of user's satisfaction with the 
price and probably improved availability following implementation of AMFm .

The higher rate of ACT use and the lower rate of CQ use among females compared to males in this study may be due to the fact that females are more likely to receive health education regarding malaria control as a result of antenatal care visit [15-16].

TABLE 3: KNOWLEDGE AND ATTITUDE TOWARD MALARIA TREATMENT.

\begin{tabular}{|c|c|c|}
\hline \multirow{2}{*}{\multicolumn{3}{|c|}{$\begin{array}{l}\text { Knowledge/Attitude } \\
\text { What is the currently recommended drugin malaria } \\
\text { treatment policy? }\end{array}$}} \\
\hline & & \\
\hline Chloroquine & 85 & (27.42) \\
\hline S/P-Fansidar, Amalare.t.c & 92 & (29.68) \\
\hline ACT e.gCoartem & 18 & (5.81) \\
\hline Artesunate alone & 18 & (5.81) \\
\hline Ampicilin & 32 & (10.32) \\
\hline Cotrimoxazole & 28 & (9.03) \\
\hline Others & 37 & (11.94) \\
\hline \multicolumn{3}{|l|}{$\begin{array}{l}\text { Drug used during the last } \\
\text { episode of malaria? }\end{array}$} \\
\hline Chloroquine & 123 & (39.62) \\
\hline S/P-Fansidar, Amalare.t.c & 120 & (38.71) \\
\hline ACT e.gCoartem & 42 & (13.55) \\
\hline Artesunate alone & 8 & (2.58) \\
\hline Ampicilin & 7 & (2.26) \\
\hline Cotrimoxazole & 5 & (1.61) \\
\hline Others & 5 & (1.61) \\
\hline \multicolumn{3}{|c|}{ Who prescribe the drug to you? } \\
\hline Doctor & 133 & (42.90) \\
\hline Nurse & 39 & (12.62) \\
\hline Chemist & 73 & (23.62) \\
\hline Self & 48 & (15.53) \\
\hline Friend & 16 & (5.16) \\
\hline \multicolumn{3}{|c|}{$\begin{array}{l}\text { What did you like most about } \\
\text { the used drug? }\end{array}$} \\
\hline Good price & 15 & $(4.84)$ \\
\hline Efficacy & 231 & (74.52) \\
\hline No side effect & 18 & $(5.81)$ \\
\hline Taste & 18 & (5.81) \\
\hline Convenient. & 28 & $(9.02)$ \\
\hline
\end{tabular}

Though closely followed by SP $4(26.7 \%)$ and CQ $3(20.0 \%)$, the fact that the price of ACT 5(33.3\%) was what users liked most about these drugs suggested that effect of the recent aggressive subsidy mechanism by AMFm to lower the price ACT is being felt in this part of the country [13].

Surprisingly, participants rated the efficacy of CQ $(44.2 \%)$ and SP $(38.1 \%)$ above that of ACT (12.6\%) contrary to available evidence from clinical trials [1718]. This may explain why these older drugs were still largely used in this community despite the perceived satisfaction with the price of ACT.

This contradiction is probably because therapeutic efficacy trials evaluate clinical and laboratory evidence in children below the age of 5 years while this study sought testimonies of adult antimalarial users. It may also be due to the fact that ACTs used in therapeutic efficacy trials are usually of certified quality [19] while drugs used by patients come from the open market. The latter possibility is supported by the recent findings of widespread substandard and fake ACTs in Nigerian drug market [12-13]. Testimonies of the end users may also explain the observed high rate of $\mathrm{CQ}$ and SP prescription by doctors and nurses in this study.

\section{Conclusion}

This study showed that though chloroquine and sulphadoxine/pyrimethamine were still the major anti-malarial drugs currently used in this part of Nigeria, there was an improvement in ACT use when compared to years before AMFm implementation. Antimalarial use practices are significantly associated with who prescribe the drugs,

knowledge of the current treatment guidelines as well of perception of efficacy by the users. Users liked the price of ACT but still believed in the efficacy of the older drugs. In addition to sustaining the current price control, there is a need to continuously monitor and effectively regulate the quality of the ACTs in circulation so as to gain the confidence of both the prescribers and the end users regarding efficacy and adherence to ACTs. This will help to safeguard the huge investment in ACT subsidy by the Roll Back Malaria partners.

\section{ACKNOWLEDGEMENT}

We are grateful to Dr Jorgen Kurzthals, Center for Medical Parasitology, Copenhagen University, Denmark for his wonderful contribution during the write up of this manuscript.

\section{Conflict of Interest}

We declare that there are no conflicts of interest associated with this study

\section{Contribution of Authors}

We declare that this work was done by all the 6 authors named in this article and all liabilities pertaining to claims relating to the content of this article will be borne by the authors. Authors AME and AF conceived the study. Authors EAM, FA, KB andMOB designed the study. The data presented in this study was collected and analyzed by Authors; EAM, OOO, MOB andOEI. The write-up was done by EAM and KB. 
TABLE 4-: RELATIONSHIP BETWEEN SOCIODEMOGRAPHIC PARAMETERS OF THE PARTICIPANTS AND THE DRUG USED TO TREAT THE LAST MALARIA EPISODE.

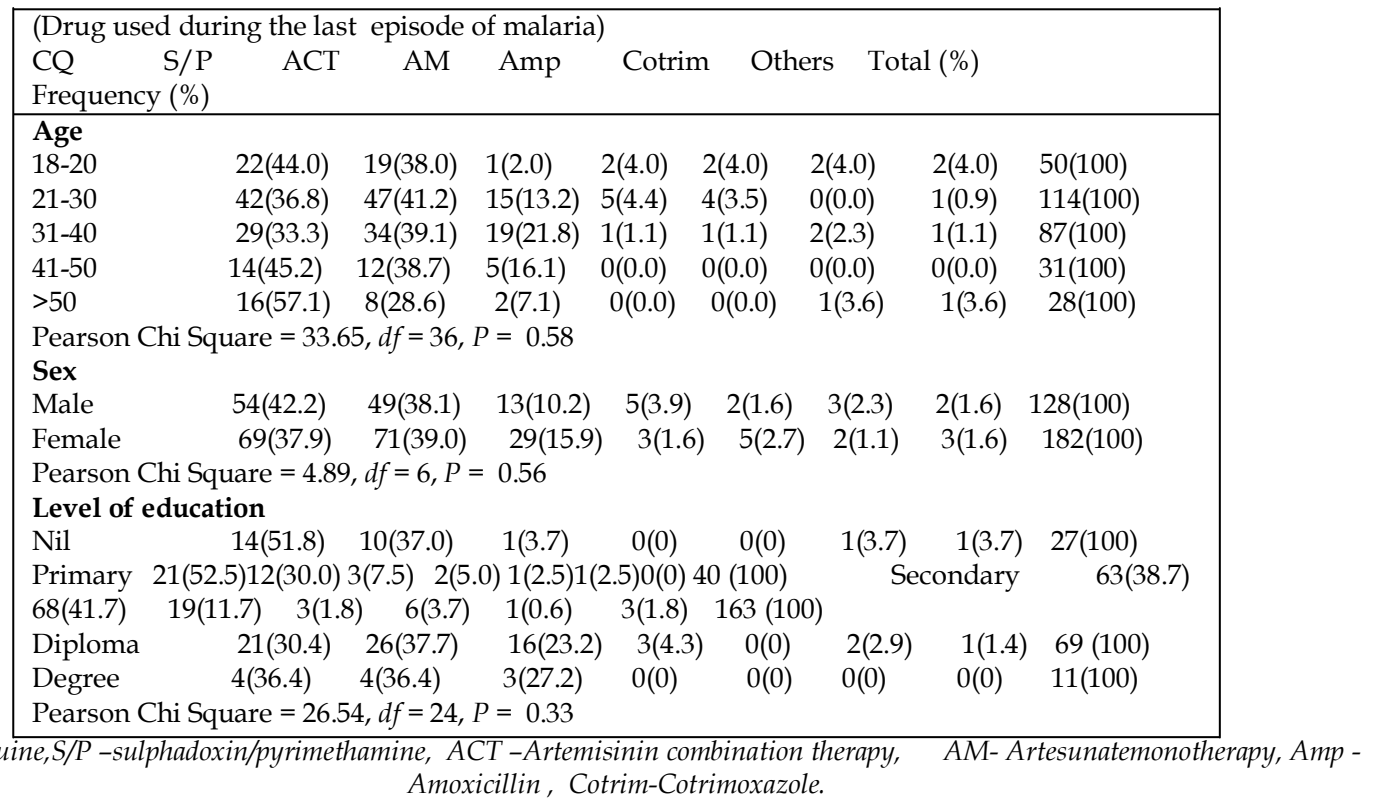

$C Q$-choroquine, S/P-sulphadoxin/pyrimethamine, ACT-Artemisinin combination therapy, AM-Artesunatemonotherapy, Amp -
Amoxicillin, Cotrim-Cotrimoxazole. Amoxicillin, Cotrim-Cotrimoxazole. 


\section{TABLE 5: RELATIONSHIP BETWEEN THE DRUGS USED TO TREAT THE LAST MALARIA EPISODE AND THE DRUG PRESCRIBER, WHAT THE USER LIKED MOST ABOUT THE DRUG AND THE USER'S KNOWLEDGE OF CURRENTLYRECOMMENDED ANTI-MALARIA DRUGS.}

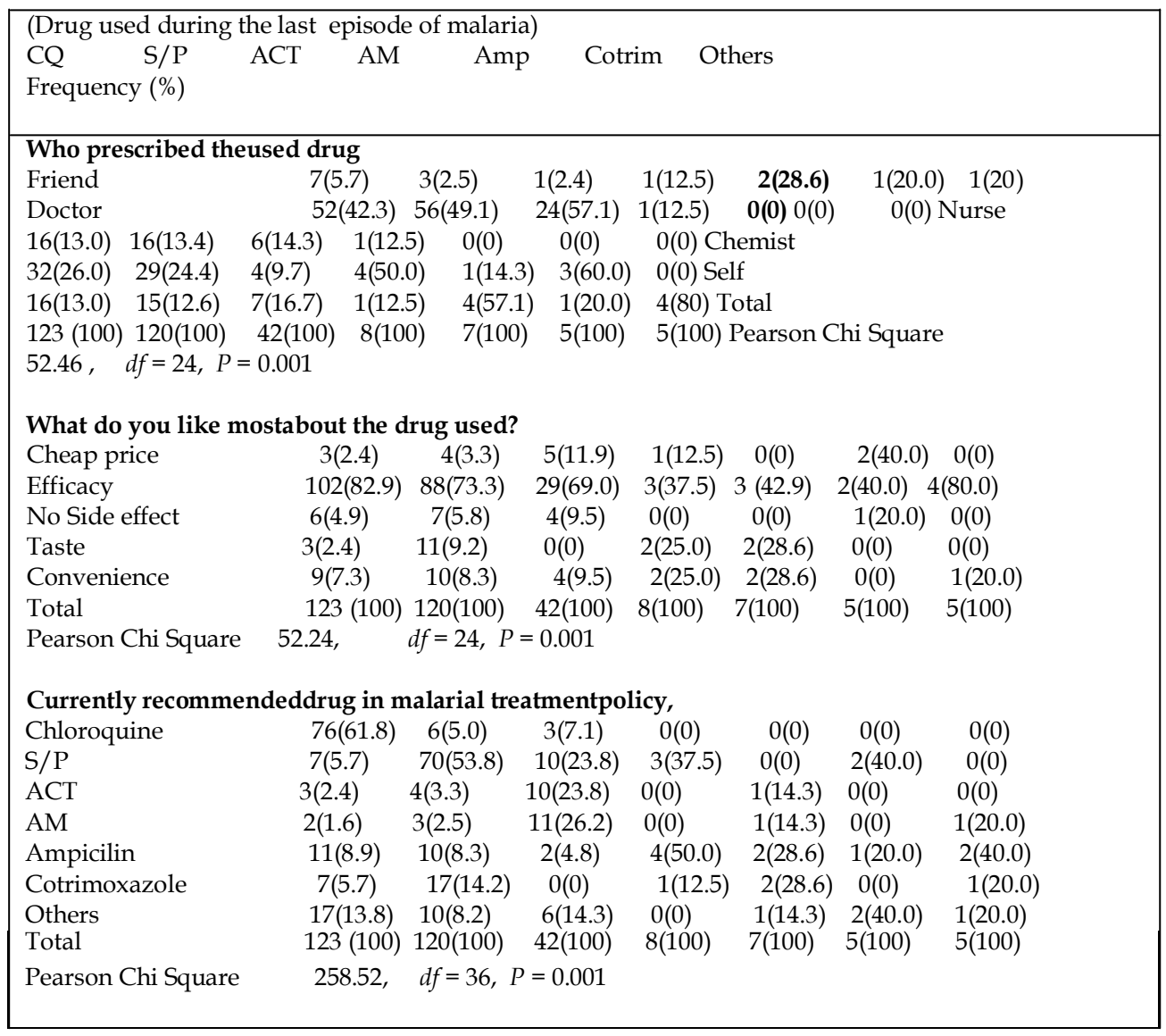

CQ-choroquine, S/P-sulphadoxin/pyrimethamine, ACT-Artemisinincombination therapy,

AM-Artesunatemonotherapy, Amp-Amoxicillin, Cotrim-Cotrimoxazole

\section{REFERNCES}

1. World Health Organization: World Malaria Report: Interventions to ControlMalaria. WHO. 2008.

2. Frosch AEP, Venkatesan M, Laufer KM. Patterns of chloroquine use andresistance in sub-Saharan Africa: a systematic review of household survey and molecular data. Malar J 2011;10:116-126

3. Meremikwu M, Okomo U, Nwachukwu C, Oyo-Ita A, Eke-Njoku J, Okebe J,Oyo-Ita E, Garner P. Antimalarial drug prescribing practice in private and publichealth facilities in South-east Nigeria: a descriptive study. Malar J 2007; 6:55-58
4. Sangaré RL, Weiss NS, Brentlinger PE, Richardson BA, Staedke SG, KiwuwaMS, Stergachis A. Patterns of anti-malarial drug treatment among pregnant women in Uganda. Malar J 2011; 10:152-160

5. West P, Wright D, Wright J. What's the evidence that NICE guidance has beenimplemented? Results from a national evaluation using time series analysis, auditof patients' notes, and interviews BMJ 2004; 329:999-1007.

6. Zucker RJ, Ruebush KT, Obonyo C, Otieno J, and Campbell CC. The mortalityconsequences of the 
continued use of chloroquine in Africa: Experience in Siaya,Western Kenya. Am J TropMedHyg 2003; 68: 386-390

7. World Health Organization. World malaria report 2011.

8. Efunshile M, TamramatRunsewe-Abiodun, BeniamGhebremedhin WolfgangKoenigand Brigitte Koenig. Prevalence of the molecular marker of chloroquine

resistance (pfcrt 76) in Nigeria 5 years after withdrawal of the drug as first-lineantimalarial: A cross-sectional study SAJCH 2011; 5: 39-41

9. Ukwe CV, Ekwunife OI. Drug utilisation study of antimalarials for the treatmentof hospitalised children under five in south-eastern Nigeria.PharmacoepidemiolDrug Saf 2008; 17:11831188.

10. Etuk EU, Egua MA, Muhammad AA. Prescription pattern of antimalarial drugs inchildren below 5 years in a tertiary health institution in Nigeria.Ann Afr Med2008;7: 24-28.

11. Bloland PB. Drug resistance in malaria.World Health Organization. 2001

12. Survey of the quality of selected antimalarial medicines circulating in six

countries of sub-Saharan Africa. Quality Assurance and Safety: Medicines

Essential Medicines and Pharmaceutical Policies.WHO. 2011.

13. Bate1 R, Hess K, Tren R, Mooney L, Cudjoe F, Ayodele T, Attaran A.Subsidizing artemisinin-based combination therapies: a preliminary investigation of the Affordable Medicines Facility - malaria . Research and Reports in TropicalMedicine 2012; 3: 16.
14. Population and location of Oke-iho. Downloaded of 28-08-2012 from

http://www.maps-streetview.com/Nigeria/Oke-Iho

15. World Health Organization. A strategic framework for malaria prevention and

control during pregnancy in the African region, Brazzaville: WHO RegionalOffice for Africa.WHO. 2004.

16. Ouma P, Van Eijk AM, Hamel MJ, Parise M, Ayisi JG, Otieno K, Kager PASlutsker L. Malaria and anaemia among pregnant women at first antenatal clinicvisit in Kisumu, western Kenya. Tropical Medicine and International Health 2007; 12 :1515-1523.

17. Michael OS, Gbotosho GO, Folarin OA, Okuboyejo T, Sowunmi A, Oduola AMJ

HappiCT . Early variations in Plasmodium falciparum dynamics in Nigerianchildren after treatment with two artemisinin-based combinations: implications on delayed parasite clearance. Malar J 2010; 9:335-343

18. Gbotosho GO, Sowunmi A, Okuboyejo TM, Happi CT, Folarin OA, Michael OS,Adewoye EO. Therapeutic efficacy and effects of artemetherlumefantrine andartesunateamodiaquinecoformulated or copackaged on malariaassociated

anemia in children with uncomplicated Plasmodium falciparum malaria inSouthwest Nigeria. Am J Trop Med Hyg 2011; 84:813-819.

19. World Health Organization Methods for surveillance of antimalarial drug

efficacy. WHO Geneva. 2009. 